treatment (specifically in Italy) reads like an advertisement for this form of therapy. Ultimately, the book raises a number of thoughtprovoking questions that should be important to both health care professionals and the general public.

\section{Saheli Sadanand}

Yale Graduate School of Arts \& Sciences

Integrated Molecular Evolution. By Scott Orland Rogers. Boca Raton: CRC Press; 2012. 391 pp. US $\$ 91.99$ Hardcover. ISBN: 978-14398199551.

Integrated Molecular Evolution by Scott Orland Rogers lives up to its name. The book covers all aspects of molecular evolution in a comprehensive manner. Nothing is assumed. The author begins with the basics and incorporates chemistry, history, and geology when required. The drawback of this approach, however, is that the identity of the target audience is unclear. The constant return to the fundamentals of biology and genetics may grow tiresome to an expert, but the inclusion of so many quantitative details and descriptions of every exception to the rule may overwhelm beginning students.

Overall, there is a strange discontinuity between the simple prose, avoidance of jargon, wealth of analogies, and the depth and breadth of the material presented. A huge quantity of facts is outlined, and although there are a lot of details, few if any generalizations are made. The trouble with all these details is that there is no way for a student to determine which facts are the important ones and which do not need to be memorized. Therefore, this book would not be appropriate for a class setting, though perhaps a particularly ambitious student would enjoy it.

The book is laid out like a course on molecular evolution and begins very basically, with the definition of life, an overview of earth's history, and a primer on genetics before addressing the more particular problems of molecular evolution, including horizontal gene transfer, classification into phylogenetic trees, and a number of chapters that discuss the entire genome of differ- ent organisms. The index is extensive, but the text is dense, with few section breaks and no key terms, although "key points" are provided at the end of each chapter as a summary. In addition, the figure legends often restate many of the important ideas from the main text and may provide a good shortcut for catching the main points without needing to read every page.

Still, there are gems of information scattered throughout the book. For example, I was intrigued to learn that the measles virus sometimes integrates into the genome of its host, and years after a patient has recovered from the infection, expression of measles virus genes in the patient's brain cells causes brain lesions that eventually lead to death (p. 158). Many topics are introduced with an historical approach, describing who discovered what when and how ideas have changed over time. There are several interesting evolutionary explanations, and the author carefully explains his rationale for each conclusion. Furthermore, the text does serve a useful purpose as a repository of numerous detailed and informative charts and graphs. The difficulty is in having enough patience to find these intriguing facts among the pages and pages of mundane details.

Jamie Schwendinger-Schreck
Department of Molecular, Cellular
and Developmental Biology
Yale University

Atlas of Neuroanatomy for Communication Science and Disorders. Edited by Leonard L. Lapointe. Illustrations by Markus Voll and Karl Wesker. New York: Thieme Medical Publishers, Inc.; 2012. 176 pp. US \$69.99 Paperback. ISBN: 978-1604066494.

The Atlas of Neuroanatomy for Communication Science and Disorders, which is part of the Atlas of Anatomy Series, is a beautifully illustrated, full-color guide to human neuroanatomy in communication and brain-based disorders. The atlas is divided into six major sections, and there is also a 